\title{
A TUTELA COLETIVA COMO FATOR DE DEMOCRATIZAÇÃO DO ESTADO E DE REALIZAÇÃO DOS DIREITOS FUNDAMENTAIS
}

\author{
THE CLASS ACTIONS AS A FACTOR OF DEMOCRATIZATION OF THE STATE AND OF \\ REALIZATION OF THE FUNDAMENTAL RIGHTS
}

\begin{abstract}
Luciano Picoli Gagno
Doutor em Direito Processual pela USP. Professor de Processo Civil na Faculdade de Direito de Vitória - FDV e na Universidade Vila Velha UVV

luciano.gagno@uvv.br
\end{abstract}

Resumo: Nesta pesquisa foi explorado o problema relativo à seguinte questão: a tutela coletiva dos direitos seria um fator que contribui com a democratização dos Estados e com a realização dos direitos fundamentais? A pesquisa teve por objetivo investigar se a democracia é um direito fundamental realizável em diferentes níveis conforme as possibilidades fáticas e jurídicas existentes, e se a tutela coletiva dos direitos atende a ela e a outros direitos fundamentais. Buscou-se ainda, analisar quais elementos são essenciais aos regimes democráticos, identificando-se como tais especialmente a participação ampla e igualitária, cujo grau de satisfação varia conforme a presença de fatores de democratização, dos quais se destaca a redução das desigualdades categóricas, concluindo-se, com base no método dedutivo e na técnica de exploração bibliográfica, que a tutela coletiva é um fator de democratização baseado na redução das desigualdades categóricas, intimamente ligado aos elementos de participação ampla e igualitária.

Palavras-chave: Democracia. Tutela coletiva. Direitos fundamentais. Elementos democráticos. Fatores de democratização.

Abstract: In this research, was explored a problem related to the following question: would the class actions to be a factor that contributes to the democratization of States and the realization of the fundamental rights? The research aimed to investigate whether democracy is a fundamental right realizable at different levels according to the factual and legal possibilities that exist, and whether the class actions it's important for her and other fundamental rights. We also sought to analyze which elements are essential to democratic regimes, identifying as such, especially broad and isonomic participation, whose degree of satisfaction varies according to the presence of democratization factors, of which the reduction of categorical inequalities stands out, concluding, based on the deductive method and the technique of bibliographic exploration, that the class actions is a democratization factor based on the reduction of categorical inequalities, closely linked to elements of broad and equal participation.

Keywords: Democracy. Class actions. Fundamental rights. Democratic elements. Factors of democratization.

\section{Para citar este artigo}

\section{ABNT NBR 6023:2018}

GAGNO, Luciano Picoli. A tutela coletiva como fator de democratização do estado e de realização dos direitos fundamentais. Prisma Jurídico, São Paulo, v. 19, n. 1, p. 60-75, jan./jun. 2020.

http://doi.org/10.5585/prismaj.v19n1.14711. 


\section{Introdução}

Como o próprio título sugere, a presente pesquisa tem por objetivo analisar os impactos que a tutela coletiva dos direitos (difusos, coletivos stricto sensu e individuais homogêneos) traz para os regimes democráticos e para a realização dos direitos fundamentais, com a finalidade de se concluir pela necessidade de ampliação dos mecanismos que viabilizam a sua utilização ou não.

Nesse cenário, a questão que se coloca como problema fundamental de nossa pesquisa é: a tutela coletiva dos direitos contribui para o aprimoramento da democracia no Estado e para a realização dos direitos fundamentais?

Para se alcançar uma resposta sobre o questionamento que norteia esta pesquisa, necessariamente será percorrida uma rota, que passará pela análise dos direitos fundamentais e sua relação com a democracia e o processo coletivo, investigando-se importantes pontos como: a democracia é um direito fundamental? A tutela coletiva é relevante para a realização de direitos fundamentais, especialmente de segunda e terceira dimensão? Qual é o significado dos direitos fundamentais?

Num segundo momento, será desenvolvida uma investigação mais aprofundada sobre o conceito e espécies de democracia, quais fatores são importantes para o seu fortalecimento e quais elementos podem ser considerados típicos de um Estado democrático?

Já na terceira etapa da pesquisa será avaliada a interação existente entre a tutela coletiva dos direitos e os fatores de democratização da sociedade, bem como entre o uso do processo coletivo e os elementos caracterizadores de um Estado democrático, investigando-se se o uso de tal ferramenta contribui com a democratização do Estado, constituindo um elemento típico da democracia moderna, especialmente da democracia participativa, que hodiernamente influencia importantes regimes democráticos, que preceituam em suas constituições alguns mecanismos de participação direta, equilibrando o caráter representativo típico do modelo hegemônico disseminado a partir da segunda metade do século passado, com uma ampliação da participação dos cidadãos, conformando o que conhecemos como democracia semidireta ou mista.

Sendo assim, passa-se no tópico subsequente a investigação dos direitos fundamentais e sua relação com a democracia e a tutela coletiva, para sabermos se a democracia é um direito fundamental, se o processo coletivo é importante para a proteção de direitos fundamentais sociais e difusos, qual o significado dos direitos fundamentais e a forma de sua aplicação nos casos em concreto. 


\section{$1 \mathrm{O}$ direito fundamental à democracia e a importância da tutela coletiva para os direitos fundamentais}

Os direitos fundamentais se caracterizam pela sua estrutura principiológica, com alto grau de abstração e generalidade (ALEXY, 2008, p. 87), devido à utilização de termos vagos e cláusulas gerais que traduzem uma abertura semântica e estrutural, cujo significado será preenchido no caso em concreto (ALEXY, 2008, p. 70-71), de modo a permitir a sua realização em diferentes níveis, de acordo com as possibilidades fáticas e jurídicas (ALEXY, 2008, p. 90), apresentadas pela tessitura de princípios e valores constitucionais convergentes e antagônicos, que devem se equilibrar para o oferecimento de decisões proporcionais.

Nesse cenário os direitos fundamentais são discernidos como mandamentos de otimização, que impõem a realização de algum valor na maior medida das possibilidades fáticas e jurídicas, ou seja, em diferentes graus, conforme as referidas condicionantes (ALEXY, 2008, p. 90).

De acordo com as suas características alguns direitos fundamentais poderão ser realizados especialmente por práticas negativas, de abstenção por parte do Estado de intervenção nas relações privadas (ALEXY, 2008, p. 258), status negativo que tradicionalmente se atribui aos direito fundamentais de liberdade, conhecidos como os direitos fundamentais de primeira dimensão (CANOTILHO, 2003, p. 362).

Outros direitos fundamentais exigem diretamente uma prestação positiva do Estado para a sua realização, status positivo que a doutrina identifica como sendo uma característica marcante dos direitos fundamentais sociais, de segunda dimensão (MARINONI, 2006, p. 193), apesar da discussão que pode ser estabelecida sobre tais premissas (NOVAIS, 2010, p. 128).

A doutrina identifica que essas prestações positivas podem ser de proteção, organização e procedimento, e prestação em sentido estrito (direitos fundamentais sociais ALEXY, 2008, p. 445), sendo que, dependendo da natureza da prestação o Estado a realizará especialmente por meio de prestações fáticas, com o investimento de recursos financeiros - o que poderia ser feito até por um particular, ou por meio de prestações normativas, de elaboração (Legislativo) e interpretação de normas jurídicas (Judiciário - ALEXY, 2008, p. 442).

Os direitos fundamentais vêm evoluindo desde a sua concepção positiva em diplomas normativos, fenômeno que se destaca especialmente a partir século XVIII com a Declaração de Independência norte-americana e a Declaração dos Direitos do Homem e do Cidadão (COMPARATO, 2003, p. 102-104 e 129-130). 
Nessa primeira dimensão, a doutrina reconhece aos direitos fundamentais o papel central de proteção da liberdade individual contra as intervenções do Estado, direitos civis e políticos que impediam o Estado de interferir em liberdades básicas (CANOTILHO, 2003, p. 360-362), tais como: ir e vir, negociar, se casar e trabalhar.

Em sua segunda dimensão, os direitos fundamentais passaram a abranger bens e valores sociais que devem ser prestados pelo Estado, exigindo prestações positivas com mais nitidez, a fim de que fosse realizado o bem estar social projetado pelas Constituições do inicio do século XX, recebendo destaque especial da doutrina a Constituição Mexicana de 1917 e a Constituição Alemã de 1919 (conhecida como a Constituição de Weimar, cidade da Saxônia região alemã, onde foi elaborada e votada - COMPARATO, 2003, p. 174 e 191). Nesse cenário floresceram especialmente os direitos: trabalhista, previdenciário e à educação pública.

A partir de 1960, pós Segunda Guerra, é percebida a terceira dimensão dos direitos fundamentais, consistente na tutela de direitos difusos nos mais diversos diplomas constitucionais, que passam a prever a proteção do meio-ambiente, da economia, do desenvolvimento e os povos, que passam a ter direito indivisíveis reconhecidos (CANOTILHO, 2003, p. 362-363).

Os direitos de quarta dimensão são constatados especialmente a partir da década de 80, com a proliferação de diplomas constitucionais garantidores da democracia, da informação e do pluralismo (BONAVIDES, 2013, p. 590). Na visão de CANOTILHO os direitos democráticos de participação política seriam de segunda dimensão (CANOTILHO, 2003, p. 362), devendo ser preservados e desenvolvidos pelo Estado, com práticas fáticas e normativas que permitam o alcance desse valor.

Percebida a democracia como um direito fundamental, pode-se dizer que ela constitui por tanto um princípio democrático de participação, que como tal deve ser entendido como um mandamento de otimização (ALEXY, 2008, p. 90), para a realização da participação democrática na maior medida das possibilidades fáticas e jurídicas existentes.

Para tanto, se fazem necessárias tanto práticas de abstenção como também e principalmente práticas positivas, visando a sua realização máxima por meio de prestações fáticas (em sentido estrito), que custeiem o seu desempenho mediante eleições e outros institutos, e prestações normativas, de proteção, organização e procedimento (NOVAIS, 2010, p. 128), que positivem e assegurem a sua realização ampla e substancial, com o auxilio das instituições existentes. 
Chega-se, portanto, ao ponto central da ideia desenvolvida neste tópico, que concerne ao fato da democracia ser um direito fundamental (BONAVIDES, 2013, p. 590) e, portanto, ter de ser realizado na maior medida das possibilidades fáticas e jurídicas existentes (ALEXY, 2008, p. 90), com o investimento de recursos e com a criação (Legislativo) e interpretação (Judiciário) de normas jurídicas (ALEXY, 2008, p. 442), voltadas à sua implementação ampla e substancial.

Tal objetivo, dentre outras formas, poderá ser alcançado por meio da tutela coletiva dos direitos, conforme se verá mais adiante, seja porque a tutela coletiva permite a participação da sociedade na proteção de bens difusos e coletivos, que são indivisíveis e, dessa forma, pertencem à coletividade, exigindo um formato novo e diferente de proteção, seja porque permite a proteção de bens que, mesmo sendo individuais, possuem uma base fática homogênea, devendo ser tratados de maneira uniforme e podendo ser tutelados igualmente para toda a coletividade, permitindo a proteção de grupos vulneráveis e a tutela de lesões cujos valores são ínfimos.

Nesse cenário, merece destaque a ligação existente entre democracia e a ordem jurídica constitucional (TOCQUEVILLE, 1998, p. 113-115), principalmente com valores como liberdade e igualdade, permitindo-se afirmar que toda ferramenta de preservação e efetivação da ordem jurídica constitucional contribui em alguma medida com a democracia, especialmente se essa ferramenta permitir a participação social na tomada de decisões sobre bens comuns ou que pertençam à coletividade.

Destarte, a tutela coletiva dos direitos permite a proteção de bens difusos e coletivos intimamente ligados à participação democrática, como por exemplo: o meio ambiente, o patrimônio cultural, estético, artístico, histórico, econômico, e outros, como também a proteção de outros direitos fundamentais, como por exemplo: os direitos sociais à saúde e à educação, os direitos dos consumidores, ficando patente nesse ponto a imbricação existente entre democracia, tutela coletiva e direitos fundamentais, já que a democracia também é um direito fundamental (BONAVIDES, 2013, p. 590), realizado em maior medida pela tutela coletiva, que além de ampliar a influência da sociedade sobre os rumos dos bens coletivos, também é importante na proteção de outros direitos fundamentais.

No tópico que segue, se tentará demonstrar com maior clareza a importância da tutela coletiva para a realização do direito fundamental à democracia numa maior medida. 


\section{Os fatores de democratização e os elementos de um regime democrático}

O conceito de democracia vem evoluindo ao longo do tempo, assim como a sua forma de realização. Se no inicio, em Atenas, há 2.500 anos, a participação era apenas para cidadãos (homens adultos, livres e atenienses - TILLY, 2013, p. 40), no século XX a democracia se dissemina e se amplia, permitindo a participação de mulheres e outros seguimentos até então excluídos em muitos regimes, independentemente de rendas ou bens (TILLY, 2013, p. 42).

O governo pelo povo (demokratia - TILLY, 2013, p. 40) tem como valor central a participação, que deve ser a mais ampla e igualitária (TILLY, 2013, p. 28), para que se alcance o maior nível de democracia possível, já que esta, sendo um direito fundamental de quarta dimensão (BONAVIDES, 2013, p. 590), poderá ser realizada em diferentes níveis, na medida das possibilidades fáticas e jurídicas (ALEXY, 2008, p. 90), com a observância da ponderação e da proporcionalidade, devido ao seu conteúdo vago, axiológico e altamente genérico (ALEXY, 2008, p. 87-88), que convive com princípios conflitantes e condizentes numa tessitura normativa complexa, além de limitações materiais, que dificultam ainda mais o seu manejo.

Boa parte da sua evolução se dá nos séculos XIII e XIV, com a Magna Carta e o surgimento e posterior oficialização do parlamento (REINO UNIDO), bem como com a revolução gloriosa, no século XVII (COMPARATO, 2003, p. 90), tendo todos esses eventos ocorridos na Inglaterra. Posteriormente, no século XVIII, com a independência norteamericana (COMPARATO, 2003, p. 102-103) e com a Revolução Francesa, que se sucedeu em inúmeros excessos e retrocessos até se estabilizar no século XX (TILLY, 2013, p. 48), se aumenta ainda mais a musculatura da democracia ao redor do mundo.

Em todos esses eventos de evolução democrática houve uma aproximação do valor participação, principal força motriz da democracia, pois todos eles foram marcados pela limitação do poder concentrado nas mãos de poucos, com a consequente ampliação dos processos de participação por meio do reconhecimento da igualdade entre pessoas que até então eram subjugadas, percebendo-se assim, como a participação ampla e igualitária são elementos essenciais da democracia, assim como a proteção da participação e o seu caráter mutuamente vinculante (TILLY, 2013, p. 28-29).

Nesse sentido, pode-se dizer que a participação ampla e igualitária se traduz em diferentes momentos de influência que o cidadão e a sociedade poderão desempenhar sobre o Estado, como se vê nas eleições periódicas com o sufrágio universal, bem como nos elementos da democracia participativa, tais como o plebiscito, o referendo, a iniciativa 
popular de projeto de lei e a ação popular (SILVA, 2014, p. 143-144), e mais modernamente com os conselhos comunitários, o orçamento participativo (MARTÍ-COSTA; PARÉS, 2009, p. 39 e 44) e todo arcabouço processual coletivo (ação popular, ação civil pública e outras), conforme se discute nesta pesquisa.

Naturalmente essa participação tem que ser garantida por lei e protegida pelo Estado, que deverá proporcionar os meios materiais e a segurança necessária para a sua realização, se submetendo, igualmente a toda a sociedade, às decisões tomadas por meio dos procedimentos democráticos e participativos (TILLY, 2013, p. 28-29).

Como fatores de democratização do Estado, TILLY identifica a construção de redes de confiança interpessoais, a redução das desigualdades categóricas e a eliminação de forças coercitivas autônomas (TILLY, 2013, p. 64 e 87-92), situações também constatadas nos cenários de democratização acima narrados, onde diversos eventos se edificaram justamente sobre novas alianças entre diferentes segmentos sociais, que se uniram para reivindicar o fim de privilégios e a redução das desigualdades que separavam conjuntos inteiros de pessoas como existia no caso do apartheid sul-africano (TILLY, 2013, p. 133-135), por exemplo, combatendo grupos armados que constituíam obstáculos a esses vetores de união e isonomia.

Em todas as revoluções democráticas mencionadas acima, que combateram privilégios e concentração de poder, em prol da participação e da igualdade, foi necessária a união entre diferentes grupos e o nivelamento das pessoas com o reconhecimento do outro (TILLY, 2013, p. 47-48, 88-91 e 101-104), seja entre burgueses e trabalhadores, como no caso francês, seja entre parlamentares, proprietários de terras e burgueses, como no caso inglês, para se combater forças contrárias, oficiais enquanto a revolução não se estabelecia, e privadas a partir do momento em que os revolucionários atingiam sua meta de poder.

Parece correta a visão de que a democracia possui uma dinâmica particular de expansão e retração constantes, pois sempre que as relações de confiança interpessoais são quebradas e processos de desigualdade categórica são implantados, o Estado se distancia do ideal de participação e democracia, o que se mostra mais destacado nos momentos iniciais de todos Estados Democráticos, sendo muito flagrante no caso francês (TILLY, 2013, p. 47-50), por exemplo, mas é um risco sempre presente e que deve sempre ser considerado.

Os elementos democráticos e fatores de democratização acima identificados independem do conceito de democracia do individuo ou do modelo de democracia desejado, sendo certo que em todos é necessária participação ampla, igualitária, protegida e mutuamente vinculante, tangível por meio da formação de redes de confiança interpessoais, pela redução 
das desigualdades categóricas e pela eliminação das forças coercitivas privadas (TILLY, 2013, p. 88-91).

O que vai variar é o grau ou a intensidade de tais fatores de realização dos elementos democráticos de participação (característica típica dos direitos fundamentais - ALEXY, 2008, p. 90), pois com a ampliação da confiança entre os sujeitos sociais, a redução das desigualdades categóricas e o aumento do reconhecimento ao próximo, e com o combate a forças coercitivas particulares, se tem uma participação cada vez mais ampla, igualitária, protegida e mutuamente vinculante.

No caso do Estado Democrático de Direito brasileiro, em que reconhecidamente se tem uma democracia mista ou semidireta, que alinha a democracia representativa a cada vez mais elementos de democracia participativa (SILVA, 2014, p. 143-145), não poderia ser diferente e o nível de realização dos fatores de democratização (confiança, igualdade e segurança) influencia o desempenho dos seus elementos de participação social (amplitude, igualdade, proteção e vinculação), influenciando o grau de democracia do nosso Estado, podendo esse nível ser elevado na medida em que se prolifere a confiança recíproca entre as instituições sociais, e em que se reduzam as desigualdades categóricas e o uso da força coercitiva privada.

Nesse sentido chega-se ao ponto central da pesquisa, de investigação da relação existente entre a tutela coletiva, os fatores de democratização e a ampliação da realização dos elementos democráticos, ou seja: o processo coletivo, como forma de proteção de direitos indivisíveis e individuais homogêneos, se identifica como algum fator de democratização, colaborando com a realização de algum elemento democrático e, portanto, com o nível de democracia do Estado?

\section{A tutela coletiva e a democratização do estado}

Como se viu no tópico anterior, um Estado Democrático pressupõe participação ampla, igualitária, protegida e mutuamente vinculante, o que se alcança em diferentes níveis dependendo de alguns fatores como: redes de confiança interpessoais, redução das desigualdades categóricas e eliminação da influência de forças coercitivas autônomas (TILLY, 2013, p. 28-29 e 88-90).

Nesse cenário, o que parece mais evidente para a pesquisa desenvolvida é a identificação da tutela coletiva dos direitos com o fator de democratização consistente na redução das desigualdades categóricas, que são aquelas que envolvem uma "conjuntos 
inteiros de pessoas que diferem coletivamente em suas oportunidades de vida" (TILLY, 2013, p. 89), como no caso do apartheid sul-africano (TILLY, 2013, p. 133-134), exemplo emblemático de desigualdade categórica, corroborado por outros casos vistos ao longo dos séculos, consistentes na limitação de direitos lastreada no gênero, na classe social ou em outros aspectos totalmente arbitrários (TILLY, 2013, p. 89), que se verificam em países com níveis baixíssimos de democracia (TILLY, 2013, p. 16-19).

Assim sendo, é possível se afirmar que quando se amplia o reconhecimento e a possibilidade de tutela de direitos para bens e setores até então ignorados ou excluídos, se tem uma redução de desigualdades categóricas e, consequentemente, uma contribuição com o nível de democracia (GAGNO; GOMES, 2019, p. 436-437), pela ampliação da participação, parecendo evidente que isso ocorra no caso de criação e aplicação de normas procedimentais (TILLY, 2013, p. 144) que aumentem a participação nos processos legislativos, ou que ampliem o direito de acesso à justiça para se discutir a violação de bens sociais indivisíveis (difusos e coletivos) e direitos individuais homogêneos, como se investiga no caso em tela.

A tutela coletiva dos direitos consiste basicamente na possibilidade de utilização de demandas coletivas, denominadas de ação popular, ação civil pública, ação coletiva, mandado de segurança coletivo, dissidio coletivo e outras, para a tutela de direitos indivisíveis (difusos e coletivos stricto sensu) e de direitos individuais homogêneos (GAGNO; SANTOS, 2017, p. 356-357).

Nesse modelo de tutela o Estado desempenha a atividade jurisdicional para proteger bens transindividuais pertencentes a pessoas indeterminadas (difusos, como o meio ambiente, por exemplo) ou ligadas por uma relação jurídica base (coletivo stricto sensu, direito de certa classe ou categoria profissional) (GAGNO; BUFON, 2020, p. 230-231), ou ainda, direitos individuais que podem ser tratados de maneira única, homogênea, devido a sua origem comum, possuindo uma base fática idêntica ou ao menos similar (WATANABE, 2000, p. 724).

O uso do processo coletivo, portanto, seja para a tutela de direitos indivisíveis (difusos e coletivos stricto sensu), seja para a tutela de direitos individuais homogêneos, se mostra fundamental para a proteção de bens e direitos fundamentais como: saúde, educação, meio ambiente, do consumidor, de concorrência, patrimônio público, dos trabalhadores, contribuintes (GAGNO; GOMES, 2019, p. 438-439) e outros, externando toda a importância que o processo coletivo tem para a sociedade e para o Estado Democrático de Direito, fundado em participação ampla, igualitária, protegida e mutuamente vinculante. 
É por meio da tutela coletiva dos direitos que a função jurisdicional pode dar uma resposta mais célere e isonômica, com economia processual e segurança jurídica (GAGNO; BUFON, 2020, p. 244), atingindo bens sociais e coletivos cujo reconhecimento e proteção eram ignorados (CAPPELLETTI; GARTH, 1988, p. 47-50), bem como pessoas que jamais ingressariam individualmente com demandas judiciais, seja pela situação de vulnerabilidade em que se encontram, seja pela baixa expressão financeira de alguns direitos individuais (ALEXANDER, 2000, p. 1. Ver também: BARBOSA MOREIRA, 1994, p. 136).

$\mathrm{Na}$ medida em que se proporciona o acesso à justiça, ou o day on a court ao individuo que afirma ter sofrido a violação a algum bem de valor jurídico para a sociedade, se amplia o nível de democracia pelo aumento do reconhecimento ao próximo e do remédio necessário a sua queixa (GAGNO; GOMES, 2019, p. 437-438), sendo certo que o Judiciário é o principal guardião da Constituição, tendo o poder inclusive de controlar a constitucionalidade das leis.

A partir do momento em que o acesso à justiça é ampliado para permitir que o cidadão ou demais legitimados demandem a proteção de bens indivisíveis, cuja possibilidade de tutela passa a ser reconhecida pelas novas normas processuais e materiais ligadas ao meio ambiente, ao consumidor, à economia, ao erário, à saúde, à educação e a tributos (GAGNO; GOMES, 2019, p. 438), por exemplo, pode-se falar de outro nível de democracia, mais agudo e qualitativo, que proporciona um maior reconhecimento do próximo e uma maior participação, pois esta não se restringe as eleições, consistindo em toda forma de reconhecimento e influência que um indivíduo possa desempenhar sobre a sociedade e o Estado, para a construção de “una comunidad autogobernada de ciudadanos” (BRUGÉ, 2009, p. 130).

O mesmo se pode dizer quando se amplia o acesso à justiça para a proteção coletiva de direitos individuais de baixo valor ou ligados a grupos vulneráveis, que dificilmente acessariam o Judiciário e participariam do regime democrático de direitos obtendo a proteção do que lhe é devido no formato individual, devido aos diversos óbices sociais, culturais e financeiros existentes.

Quando o Estado reconhece e protege no seu ordenamento jurídico e na sua práxis jurisdicional, direitos indivisíveis coletivos e direitos individuais que dificilmente seriam pleiteados individualmente, reduz a desigualdade social existente entre as vitimas da violação dos direitos, passando a reconhecê-los e protegê-los como sujeitos dignos de tanto e de forma mais eficiente (GAGNO; BUFON, 2020, p. 244).

É nesse sentido que TILLY fala da redução das desigualdades categóricas como fator de democratização, ou seja, fala da extensão do reconhecimento de direitos a grupos até então ignorados ou excluídos, que passam a participar em sentido amplo por meio de novas normas 
(TILLY, 2013, p. 89-90 e 144), sendo considerados e protegidos de forma mais isonômica e eficiente, aumentando o nível de democracia. São negros que passam a poder estudar nas mesmas escolas em que os brancos, tendo direito de buscar essa proteção junto ao Judiciário (EUA, 1954), ou mulheres que passam a ter reconhecidos os seus direitos políticos (TILLY, 2013, p. 41-42), por exemplo.

O reconhecimento e a extensão de direitos promove um nivelamento cuja existência é um pressuposto básico para se iniciar um processo de democratização, ou seja, de envolvimento da sociedade com o Estado por meio da participação (TILLY, 2013, p. 89). Nessa toada, quanto mais os direitos promoverem isonomia entre os indivíduos de uma mesma sociedade, pode-se dizer que maior será o nível de democracia, sendo certo que a democracia não convive com falta de liberdade e igualdade, princípios ou valores considerados centrais (SILVA, 2014, p. 131-134).

Nesse cenário, pode-se afirmar que também há uma ampliação no nível de democracia de um Estado, a partir do momento em que se reconhece a existência e a possibilidade de tutela de direitos individuais homogêneos, que apesar de divisíveis, muitas vezes não seriam demandados individualmente, por possuírem baixa expressão financeira (ALEXANDER, 2000 , p. 1) ou pela situação de vulnerabilidade vivenciada por grupos sociais compostos por crianças, idosos e consumidores, que dificulta o acesso à informação e/ou aos meios materiais necessários em litígios contra aqueles que abusam do poder econômico ou político (BRASIL, 2016).

Estabelecida a tutela coletiva como fator de democratização, pode-se afirmar a sua importância como elemento das democracias modernas participativas, pois mesmo que não se possa afirmar que um regime é autoritário por ele não aceitar a tutela coletiva dos direitos, pode-se dizer que ele terá um baixo nível de democracia nesse caso, já que esta é realizada em diferentes níveis, como os demais vetores axiológicos dos direitos fundamentais, que devem ser realizados na maior medida possível, dentro dos limites fáticos e jurídicos existentes (ALEXY, 2008, p. 90).

Pode-se falar assim, numa identificação do sistema de tutela coletiva dos direitos indivisíveis e individuais homogêneos com o fator de democratização redução das desigualdades categóricas, estando imbrincado com os elementos de participação ampla e igualitária, pois quanto mais isonomia no Estado, a participação (traduzida no reconhecimento e na influência) se torna mais ampla e igualitária (GAGNO, GOMES, 2019, p. 436).

Destarte, o sistema de tutela coletiva dos direitos constitui uma ferramenta interessante que contribui com a redução das desigualdades, resultando numa participação mais ampla e 
igualitária, tão anunciada pelos defensores da democracia participativa (MARTÍ-COSTA; PARÉS, 2009, p. 43-44. Em sentido similar: BRUGUÉ, 2009, p. 129), que se contrapõe ao modelo tradicional representativo (MARTÍ-COSTA; PARÉS, 2009, p. 40-41. Ver também: BRUGUÉ, 2009, p. 128-129. SILVA, 2014, p. 139 e 143), pressupondo que a participação deve ser aprofundada por meio da disseminação de informação, da criação de momentos para argumentação dos grupos envolvidos e, por fim, de deliberação, que apesar de não ser acessível a todos como num plebiscito, pode se dar de forma bem ampla com a participação criteriosa dos mais envolvidos (BRUGUÉ, 2009, p. 134-135).

A tutela coletiva dos direitos, apesar de também pressupor informação e não permitir deliberação, pois a decisão advirá da função jurisdicional provocada, possibilita a criação de momentos para argumentação, que permitirão o convencimento e a influência sobre a decisão que será proferida sobre bens de interesse público e social, não se podendo restringir a ideia de participação apenas a ferramentas de deliberação como plebiscito, referendo, conselhos populares e orçamento participativo, que apesar de serem típicas, não excluem outras como a ação popular (SILVA, 2014, p. 144) e toda manifestação de processo coletivo, que permitam a proteção de direitos sociais e coletivos, indivisíveis ou individuais homogêneos.

A democracia brasileira é reconhecidamente semidireta ou mista, por reunir elementos da democracia representativa e participativa (SILVA, 2014, p. 143 e 145. Em sentido similar: SLAIBI, 1995, p. 8. GAGNO; COUTO, 2018, p. 634-635), sendo certo que, apesar do seu nível elevado no campo do sufrágio, determinante contribuição é oferecida pela adoção de instrumentos da democracia participativa, especialmente pelo sistema de tutela coletiva dos direitos, onde apesar da decisão não ser tomada pelo cidadão mediante o voto, este participa provocando a proteção de bens difusos e coletivos (públicos e sociais) que também dizem respeito a ele, ou de direitos individuais homogêneos cuja proteção molecularizada é mais eficiente, contribuindo para o nivelamento da sociedade e redução das desigualdades fundamentais.

\section{Conclusão}

Ao final, pode-se estabelecer a seguinte conclusão geral: a tutela coletiva dos direitos contribui para a realização da democracia e de outros direitos fundamentais no maior nível possível, seja quando permite o acesso à justiça para a tutela de bens coletivos e indivisíveis, que há algumas décadas não recebiam nenhuma proteção (saúde, educação, meio ambiente, consumidor, economia), seja quando viabiliza a tutela de direitos individuais homogêneos de 
maneira mais célere e segura, de valores ínfimos e de grupos vulneráveis, pois assim, a tutela coletiva dos direitos se identifica com o fator de democratização de redução das desigualdades categóricas, alimentando os elementos que alicerçam os regimes democráticos, especialmente a amplitude e a isonomia da participação.

Para tanto, foram estabelecidas algumas premissas fundamentais, que podem ser enumeradas da seguinte forma:

1 - A democracia é um direito fundamental, que como tal, deve ser realizado na maior medida das possibilidades fáticas e jurídicas, ou seja, a participação democrática da sociedade nas decisões sobre os rumos da sociedade deve ser aumentada no maior nível possível.

2 - A tutela coletiva contribui com o direito fundamental a democracia quando permite o acesso à justiça para a tutela de bens coletivos indivisíveis, bem como quando permite o acesso à tutela de bens individuais de forma mais célere, segura, para grupos vulneráveis e cujos valores muitas vezes são ínfimos, sendo certo, que tais demandas jamais chegariam ao Judiciário no paradigma jurídico liberal positivista.

3 - A tutela coletiva também é importante para a realização de outros direitos fundamentais como saúde, educação, consumidor, tributário e meio ambiente, que passam a ser protegidos pelas constituições pátrias no século $\mathrm{XX}$ em diante, constituindo os direitos fundamentais de segunda geração em diante.

4 - Dentre as prestações positivas tendentes à realização da democracia e de outros direitos fundamentais em maior medida, destaca-se para a presente pesquisa a necessidade de criação e interpretação das normas jurídicas voltadas à regulamentação e aprimoramento do processo coletivo.

5 - Sendo um direito fundamental, a democracia pode ser realizada em diferentes níveis, variando conforme a presença dos fatores de democratização (redes de confiança interpessoais; redução das desigualdades categóricas; combate ao uso de forças coercitivas autônomas) e, consequentemente, do fortalecimento dos elementos fundantes de qualquer regime democrático (participação ampla, igualitária, protegida e mutuamente vinculante).

6 - Dentre os fatores de democratização de um Estado, destaca-se para este estudo a redução das desigualdades categóricas, pois a tutela coletiva dos direito se identifica com esse fator, na medida em que permite o reconhecimento e a proteção de bens sociais indivisíveis, difusos e coletivos, que há pouco tempo não recebiam qualquer proteção 
jurídica, bem como de grupos vulneráveis ou de vítimas de lesões de baixo valor, que dificilmente seriam objeto da atuação jurisdicional.

7 - Na medida em que o Estado passa a tutelar os bens coletivos indivisíveis que até então não tinham qualquer reconhecimento e proteção, permitindo que o cidadão ou outros entes legitimados provoquem tal atividade, passando ainda a proteger grupos de pessoas necessitadas ou lesadas em quantias ínfimas, que jamais seriam objeto de um processo individual, reduzem-se as desigualdades categóricas e aumenta-se o grau de reconhecimento dos beneficiários desses direitos, que passam a influenciar o Estado e seu funcionamento em maior medida, recebendo as respectivas respostas.

8 - Contribuindo com a redução das desigualdades categóricas, a tutela coletiva dos direitos robustece a amplitude e a isonomia da participação, que são elementos centrais da democracia, sendo certo que, além de ampla e igualitária, a participação deve ser protegida e mutuamente vinculante. É nesse cenário, com a redução das desigualdades estruturais e o fortalecimento da participação ampla e igualitária apontadas, que a democracia é satisfeita em maior medida pela tutela coletiva dos direitos.

\section{Referências}

ALEXANDER, Janet Cooper. An introduction to class actions procedure in the United States. Disponível em: <http://law.duke.edu/grouplit/papers/classactionalexander.pdf >, p. 1-26, 2000. Acesso em: 19 jul. 2018.

ALEXY, Robert. Teoria dos direitos fundamentais. Trad. Virgílio Afonso da Silva. São Paulo: Malheiros, 2008.

BARBOSA MOREIRA, José Carlos. A efetividade do processo de conhecimento. Revista de Processo, São Paulo: Revista dos Tribunais, v. 74, p. 126-137, 1994.

BONAVIDES, Paulo. Curso de direito constitucional. 28 a ed. atual. São Paulo: Malheiros, 2013.

BRASIL. Superior Tribunal de Justiça. AgInt no REsp 1573481 / PE. AGRAVO INTERNO NO RECURSO ESPECIAL 2015/0312195-6. Relator(a) Ministro HERMAN BENJAMIN (1132). Órgão Julgador T2 - SEGUNDA TURMA. Data do Julgamento: 26/04/2016. Data da Publicação/Fonte: DJe 27/05/2016. Acesso em: 19 jul. 2018.

BRUGUÉ, Quim. Calidad democrática: de la debilidade liberal a la fuerza deliberativa. In: PARÉS, Marc (coord.). Participación y calidad democrática: evaluando las nuevas formas de democracia participativa. Barcelona: Ariel, p. 121-138, 2009.

CANOTILHO, J. J. Gomes. Direito constitucional e teoria da constituição. $7^{\mathrm{a}}$ ed. Coimbra: Almedina, 2003. 
CAPPELLETTI, Mauro; GARTH, Bryan. Acesso à Justiça. Porto Alegre: Sérgio Antônio Fabris, 1988.

COMPARATO, Fábio Konder. A afirmação histórica dos direitos humanos. $3^{\mathrm{a}}$ ed. rev. e ampl. São Paulo: Saraiva, 2003.

EUA. Brown v. Board of Education. 1954. Disponível em: <https://supreme.justia.com/us/347/483/case.html>. Acesso em: 20 abr. 2018.

GAGNO, Luciano Picoli; COUTO, Camilo José D’Ávila. Ação popular por omissão lesiva ao mínimo existencial (moralidade) e controle de políticas públicas: novos horizontes desvelados ... Revista Brasileira de Políticas Públicas, Brasília, v. 8, n. 1, p. 631-647, 2018.

GAGNO, Luciano Picoli; BUFON, Fernanda Porchera. O processo coletivo e a suspensão dos processos individuais: uma análise conforme o direito fundamental de acesso à justiça.

Revista Eletrônica de Direito Processual - REDP, ano 14, v. 21, n. 1, p. 227-251, Janeiro a Abril de 2020.

GAGNO, Luciano Picoli; GOMES, Mariana Santos Camara. A restrição da tutela de direitos individuais homogêneos de natureza tributária e o direito fundamental de acesso à justiça.

Revista de Direito Brasileira, v. 23, n. 9, p. 425-444, Maio a Agosto de 2019.

GAGNO, Luciano Picoli; SANTOS, Barbara Evelyn Sad. Ensaio sobre a efetividade da tutela coletiva em Portugal. Revista Eletrônica de Direito Processual - REDP, ano 11, v. 18, n. 2, p. 347-370, Maio a Agosto de 2017.

MARINONI, Luiz Guilherme. Curso de processo civil, v. I: teoria geral do processo. São Paulo: Revista dos Tribunais, 2006.

MARTÍ-COSTA, Marc; PARÉS, Marc; et al. La participación ciudadana em la esfera pública: enfoques teórico-normativos y modelos de democracia. In: PARÉS, Marc (coord.). Participación y calidad democrática: evaluando las nuevas formas de democracia participativa. Barcelona: Ariel, p. 29-53, 2009.

NOVAIS, Jorge Reis. Direitos sociais: teoria jurídica dos direitos sociais enquanto direitos fundamentais. Coimbra: Coimbra, 2010.

SLAIBI FILHO, Nagib. Ação popular mandatória. Rio de Janeiro: Forense, 1995.

TILLY, Charles. Democracia. Trad. Raquel Weiss. Petrópolis: Vozes, 2013.

TOCQUEVILLE, Alexis. A democracia na américa: leis e costumes de certas leis e certo costumes políticos ... Trad. Eduardo Brandão. Pref. biogr. e bibliogr. François Furet. São Paulo: Martins Fontes, 1998.

REINO UNIDO. Birth of the English Parliament. Disponível em: $<$ https://www.parliament.uk/about/livingheritage/evolutionofparliament/originsofparliament/b irthofparliament/overview/>. Acesso em: 18 jul. 2018. 
SILVA, José Afonso da. Curso de direito constitucional positivo. $37^{\mathrm{a}}$ ed. rev. e atual. São Paulo: Malheiros, 2014.

WATANABE, Kazuo; et al. Código Brasileiro de Defesa do Consumidor: comentado pelos autores do anteprojeto. $6^{\mathrm{a}}$ ed. Rio de Janeiro: Forense, 2000. 